This item was submitted to Loughborough's Research Repository by the author.

Items in Figshare are protected by copyright, with all rights reserved, unless otherwise indicated.

\title{
Real time energy management of electrically turbocharged engines based on model learning
}

\section{PLEASE CITE THE PUBLISHED VERSION}

https://doi.org/10.4271/2019-01-1056

\section{PUBLISHER}

(C) SAE International

VERSION

AM (Accepted Manuscript)

\section{PUBLISHER STATEMENT}

This paper was accepted for publication in the journal SAE Technical Papers and the definitive published version is available at https://doi.org/10.4271/2019-01-1056

LICENCE

CC BY-NC-ND 4.0

\section{REPOSITORY RECORD}

Zhao, Dezong, Wen Gu, and Byron Mason. 2019. "Real Time Energy Management of Electrically Turbocharged Engines Based on Model Learning”. figshare. https://hdl.handle.net/2134/37341. 


\section{Real time energy management of electrically turbocharged engines based on model learning}

\begin{abstract}
Engine downsizing is a promising trend to decarbonise vehicles but it also poses a challenge on vehicle driveability. Electric turbochargers can solve the dilemma between engine downsizing and vehicle driveability. Using the electric turbocharger, the transient response at low engine speeds can be recovered by air boosting assistance. Meanwhile, the introduction of electric machine makes the engine control more complicated. One emerging issue is to harness the augmented engine air system in a systematical way. Therefore, the boosting requirement can be achieved fast without violating exhaust emission standards. Another raised issue is to design an real time energy management strategy. This is of critical to minimise the required battery capacity. Moreover, using the on-board battery in a high efficient way is essential to avoid over-frequent switching of the electric machine. This requests the electric machine to work as a generator to recharge the battery. The capability of generating power strongly depends on the engine operating point. One big challenge is that the calibration of generating power capability is time-consuming in experiments. This paper proposes a neuro-fuzzy approach to model the engine. Based on the virtual engine model, the capability of generating power at arbitrary engine operating point can be obtained fast and accurately, which is applicable to implement in real time.
\end{abstract}

\section{Introduction}

Engine downsizing provides great potential in improving fuel efficiency by more efficient combustion, decreased engine mass, decreased pumping losses and decreased friction losses [1-3]. The defect of engine downsizing is the performance decrement at low engine speeds. This is because using conventional turbochargers, the enthalpy in a smaller engine swept volume cannot provide enough exhaust gas [4]. Therefore, the turbocharger for boosting cannot be effectively used, as shown in Fig. 1. This problem can be significantly mitigated by mounting an high speed electric machine (EM) on the turbine shaft, between the

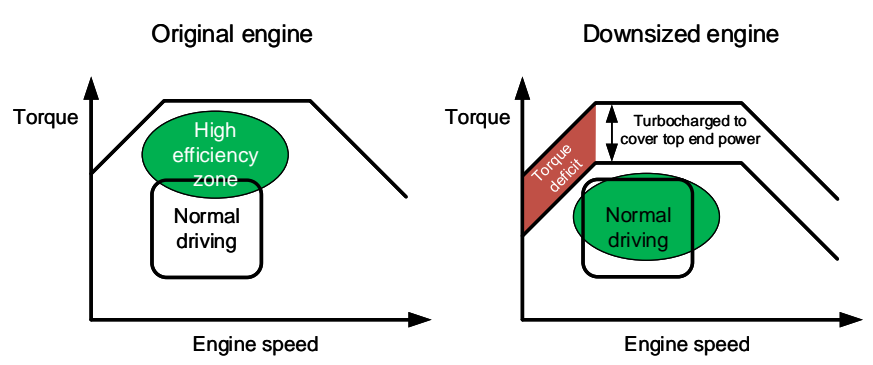

Figure 1: Benefit and limit of downsized engines

turbine and the compressor. The EM improves the transient response when it runs as a motor, and enables surplus exhaust gas energy recovery when it runs as a generator. The success of electric turbochargers is underpinned by manufacturing and control. Foremost, a reliable ultrahigh speed EM with small inertia is required to run within the compact turbocharger housing. With the advances in power electronics, the EM technology is mature enough to enable the operation at higher than $100 \mathrm{krpm}$. The increase on inertia is also well addressed. In [5], an electric turbocharger with less than $10 \%$ increase on turbine shaft inertia is reported.

The control is still challenging [6-8]. A multivariable controller is to be designed to regulate key variables in a centralised manner. Moreover, a high efficient real time energy management is essential. That is because three main targets are twisted including improving fuel efficiency, reducing exhaust emissions and enhancing transient response. The energy management strategy should work with the multivariable controller to distribute energy flows in an optimal way. In transients, the EM is required to work at the maximum motoring power to improve response. In steady states, the engine is regulated by a multivariable controller, to realise battery state-of-charge (SOC) recovery and air system control. In this case, the EM needs to run at a generator to recharge the battery. However, the allowed generating power varies at different engine operating points. This limit should not be violated or the engine will stall. It is time consuming and expensive to compute the limits in offline experimental calibrations. That is because there 


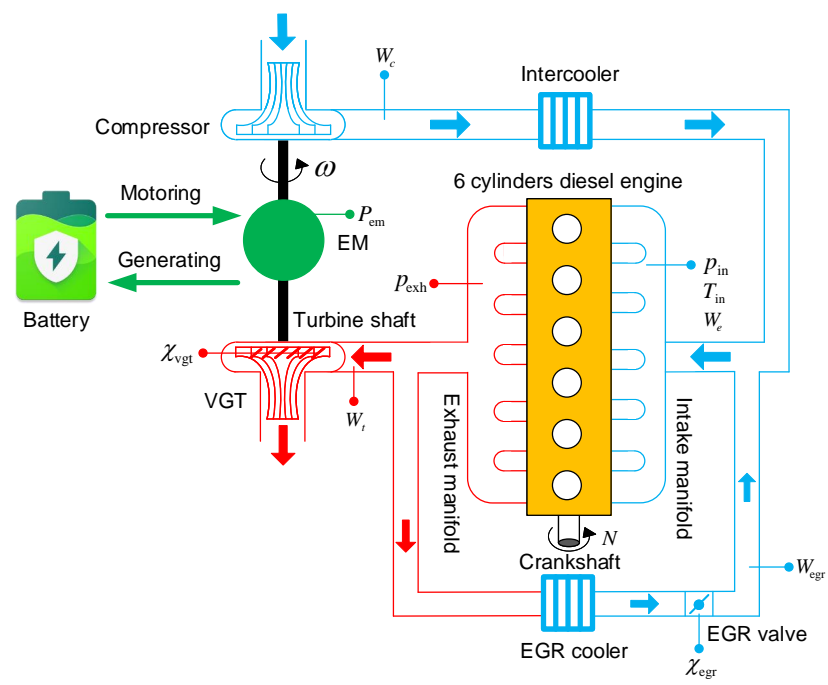

Figure 2: Electrified turbocharged diesel engine

are too many calibration points required to cover the engine operating range. Fortunately, the development of machine learning offers a great opportunity to obtain the engine model fast and accurately, which makes online calibration possible. Previous studies have shown that the exhaust pressure is a key variable in impacting the EM power. Therefore, the energy management problem is formulated as finding the best exhaust pressure setpoint to generate the required EM generating power [9].

A hierarchical energy management strategy is proposed in this paper, including the lower level control and the supervisory level control. On the supervisory level, the hierarchical local model tree (HILOMOT) method is employed to build a virtual engine model with high fidelity [10]. This provides the clear relationship between the exhaust pressure and the allowable generating power. The models in non-covered engine operating areas can be learned in a neuro-fuzzy way from the models built on calibration points. Considering the capability in dealing internal couplings and external constraints, a multivariable model predictive controller (MPC) is designed as the lower level controller [11]. The lower level controller will track the setpoints generated by the supervisory level control to implement the complete energy management and engine control.

\section{System Description}

The diagram of an electric turbocharged diesel engine (ETDE) is illustrated in Fig. 2, while the critical variables and parameters are listed in Table 1. The electric turbocharger is a single stage turbocharger consisting of a variable geometry turbine (VGT), an EM and a compressor, which are mounted on the same turbine shaft. Except the gas across the exhaust gas recirculation (EGR) valve, all the other exhaust gas passes through the ETA turbine.
Table 1: Nomenclature

\begin{tabular}{ll}
\hline Variable & Description \\
\hline$N$ & Engine speed \\
$T_{L}$ & Engine load \\
$W_{f}$ & Engine fuelling rate \\
$W_{c}$ & Fresh air flow rate \\
$W_{\text {egr }}$ & EGR mass flow rate \\
$W_{e}$ & Engine total mass flow rate \\
$W_{t}$ & Turbine gas mass flow rate \\
$P_{c}$ & Compressor power \\
$P_{t}$ & Turbine power \\
$P_{\text {em }}$ & EM power \\
$p_{\text {in }}$ & Boost pressure \\
$p_{\text {exh }}$ & Exhaust manifold pressure \\
$p_{\text {am }}$ & Ambient pressure \\
$\omega$ & Turbine speed \\
$\chi_{\text {egr }}$ & EGR valve position \\
$\chi_{\text {vgt }}$ & VGT vane position \\
\hline
\end{tabular}

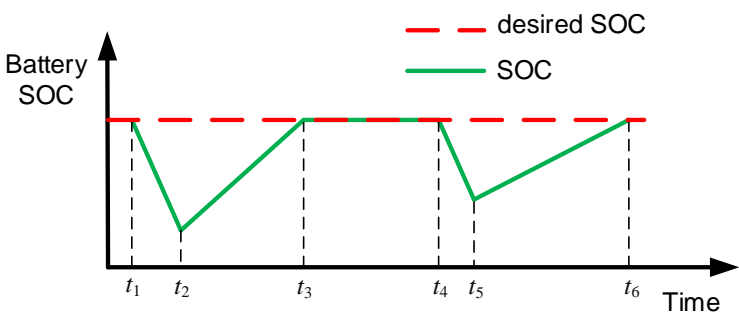

$t_{1} \sim t_{2}$ : transient period 1 , battery discharging

Operating point 1: $\left\{\begin{array}{l}t_{2} \sim t_{3}: \text { steady state, battery charging } \\ t_{3} \sim t_{4}: \text { steady state, electric machine shut off }\end{array}\right.$

$t_{4} \sim t_{5}:$ transient period 2 , battery discharging

Operating point 2: $t_{5} \sim t_{6}:$ steady state, battery charging

Figure 3: Battery SOC recovery

The expansion of the exhaust gas across the VGT rotates the compressor, and thereafter the fresh air is pumped into the intake manifold. This layout improves the engine transient response by using the EM as a motor, and enables the exhaust gas energy recovery at high engine loads by using the EM as a generator. This work is based on a latest electric turbocharger, called Electric Turbocharger Assist (ETA). Development of the ETA device is undertaken by a consortium consisting of Carterpillar Inc., Imperial College London, BorgWarner Turbo Systems, and Louhborough University. The ETA is designed based on a BorgWarner BV63 traditional turbocharger for heavy-duty diesel engine downsizing. A switched reluctance motor (SRM) is selected as the EM because of its simple structure and the resulting low cost. The SRM has a rated power of $5 \mathrm{~kW}$.

The EM provides an additional degree of freedom in engine air system regulation but also makes control more complicated. The main target of controlling the diesel engine air system is to regulate $\mathrm{NO}_{x}$ and PM. From a control point of view, the target can be achieved by matching desired 


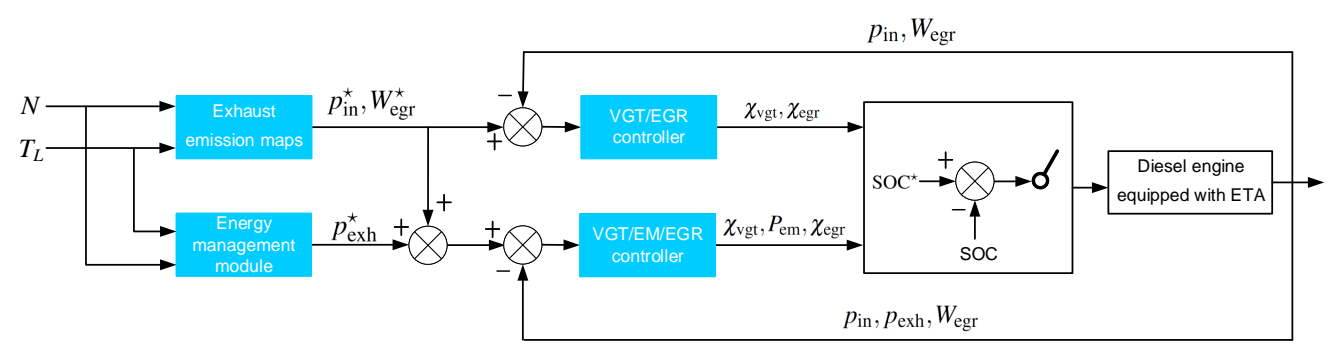

Figure 4: Full control structure

$p_{\text {in }}$ and $W_{c}$. However, in the ETDE, generating specified electrical power from the turbine rotation is an additional target. Therefore, one more independent output has to be identified. It has been proven that the exhaust pressure is the best additional output [9]. This is because the exhaust pressure directly impacts the EM power and more importantly, it is controllable.

It is expected that the energy management strategy can generate the optimal setpoint of exhaust pressure in steady states. Therefore, under the command signals of the multivariable controller, the EM can work at the maximum allowable generating power to recover the battery SOC. The desired variation on battery SOC is illustrated in Fig. 3.

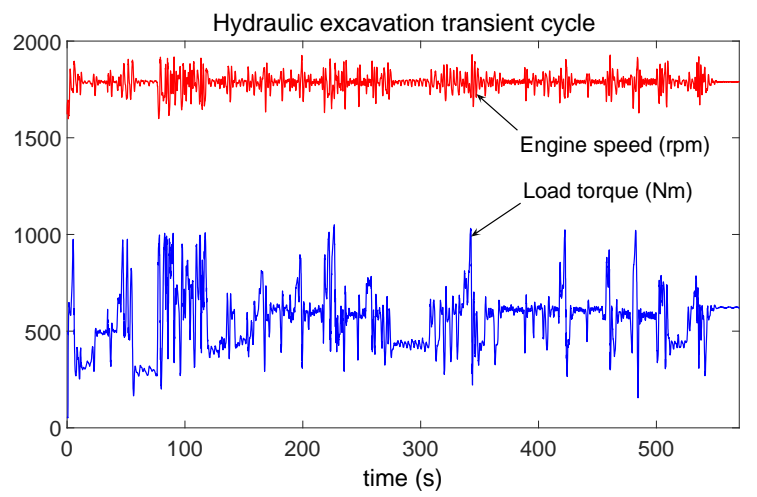

(a)

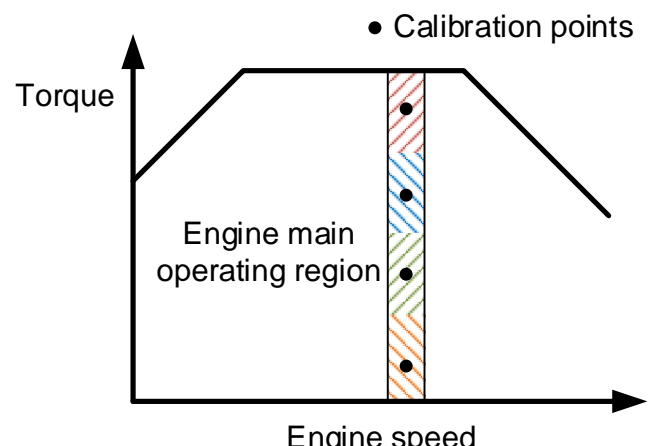

(b)

Figure 5: Engine main operating region and calibration segmentation (a) Hydraulic excavation transient cycle. (b) Calibration points.
In the transient period $\left[t_{1}, t_{2}\right]$, the EM works as a motor to support boosting. In the steady state period $\left[t_{2}, t_{3}\right], p_{\text {in }}, p_{\text {exh }}$ and $W_{\text {egr }}$ are controlled by $\chi_{\text {vgt }}, P_{\text {em }}$ and $\chi_{\text {egr }}$. In the steady state period $\left[t_{3}, t_{4}\right]$, the desired battery SOC is achieved and then EM is shut off. In this period, two variables, $p_{\text {in }}$ and $W_{\text {egr }}$ are controlled by $\chi_{\text {vgt }}$ and $\chi_{\text {egr }}$. Correspondingly, the full control structure including energy management module and lower level controllers are illustrated in Fig. 4.

\section{Lower Level Controller Design}

An Explicit MPC (EMPC) is designed to behave as the lower level controller because it computes the control laws offline. It grants the EMPC an advantage of low online computational burden while maintaining the identical performance as the MPC. The EMPC controller is synthesized offline based on the calibration data generated at selected engine operating points. For example, the hydraulic excavation transient cycle (HETC) is a typical cycle for offhighway heavy-duty engines, as shown in Fig. 5(a). The calibration points locate in the engine main operating region, as shown in Fig. 5(b). The developed controller should have robustness against the variations of engine operating point in a neighbourhood, as indicated in Fig. 5(b) using different colours.

Engine model at one operating point can be linearised as

$$
\left\{\begin{array}{l}
x(k+1)=A x(k)+B u(k)+B_{d} d(k) \\
y(k)=C x(k)+D_{d} d(k)
\end{array}\right.
$$

where $x \in \mathbb{R}^{n}, u \in \mathbb{R}^{m}$, and $y \in \mathbb{R}^{p}$ are the state vector, input vector, and output vector, respectively; $d$ is the disturbance; $A, B$, and $C$ are coefficient matrices to be identified.

The control problem is defined as the following optimisation problem:

$$
\begin{gathered}
U^{\star}(k)=\operatorname{argmin} \sum_{i=0}^{H_{p}}\left\|y(k+i)-y^{\star}(k)\right\|_{2}^{Q}+\|\Delta u(k+i)\|_{2}^{R} \\
\text { s.t. } x(k+1)=A x(k)+B u(k)+B_{d} d(k) \\
u(k)=u(k-1)+\Delta u(k) \\
y(k)=C x(k)+D_{d} d(k) \\
u_{\min } \leq u \leq u_{\max } \\
y_{\min } \leq y \leq y_{\max }
\end{gathered}
$$




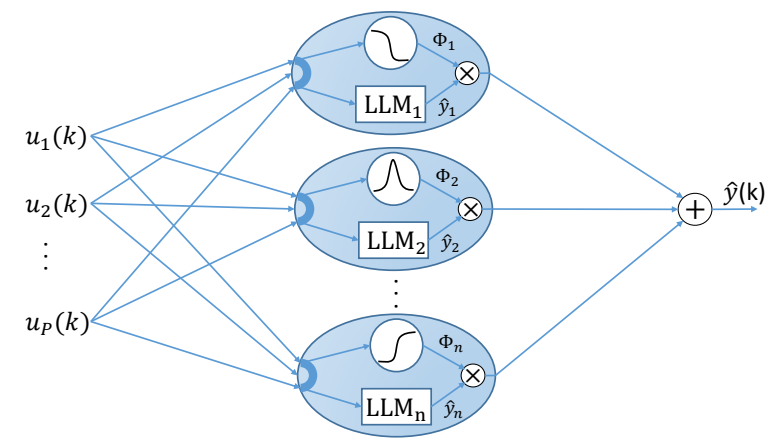

Figure 6: HILOMOT modelling structure at a local engine operating point

where

$$
\begin{aligned}
U(k) & \triangleq\left[\Delta u^{\mathrm{T}}(k), \ldots, \Delta u^{\mathrm{T}}\left(k+H_{c}-1\right)\right]^{\mathrm{T}} \\
\Delta u(k+i) & =\Delta u\left(k+H_{c}-1\right), \quad i=H_{c}, \ldots, H_{p} \\
Q & =Q^{\mathrm{T}}>0 \\
R & =R^{\mathrm{T}}>0 \\
\|x\|_{2}^{Q} & =x^{\mathrm{T}} Q x .
\end{aligned}
$$

The constraints on $u$ are the amplitude boundaries of the control signals, and the constraints on $y$ represent the physical ranges of the outputs. $H_{p}$ and $H_{c}$ are the prediction horizon and control horizon respectively and $H_{p} \geq H_{c}$ is held. The controller synthesis is completed using the Model Predictive Control Toolbox in MATLAB.

\section{Energy Management Strategy Design}

Energy management is to distribute the energy flows in an optimal way. It is achieved by online generating and tracking the optimal setpoints of $p_{\text {in }}, p_{\text {exh }}$ and $W_{\text {egr }}$, denoted as $p_{\text {in }}^{\star}, p_{\text {exh }}^{\star}$ and $W_{\text {egr }}^{\star}$. According to the vehicle exhaust emission standards relating to $\mathrm{NO}_{x}$ and particulate matter (PM), $p_{\text {in }}^{\star}$ and $W_{\text {egr }}^{\star}$ are generated from offline characterisation. The value of $p_{\text {exh }}^{\star}$ would be updated online to attract the battery SOC back to $\mathrm{SOC}^{\star}$, where $\mathrm{SOC}^{\star}$ is the desired value of battery SOC. In this research, $\mathrm{SOC}^{\star}=1$ is expected. This is to downsize the required capacity of battery.

The core idea of online energy management is to generate the $p_{\text {exh }}^{\star}$ to activate the EM working as a generator. This is achieved by precise mapping between $P_{\mathrm{em}}$ and $p_{\mathrm{exh}}$. The HILOMOT method has been proven effective in modelling multivariable systems so is selected [12]. Importing the perturbation signals into the algorithm, the explicit relationships between inputs and outputs can be generated from a neuro-fuzzy way. The HILOMOT modelling structure is illustrated in Fig. 6, while each neuron behaves as a local linear model (LMN). In this work, the LMNs are expressed as polynomial functions. As an example, based on the calibration data at $(1800 \mathrm{rpm}, 800 \mathrm{Nm})$, the outputs can be

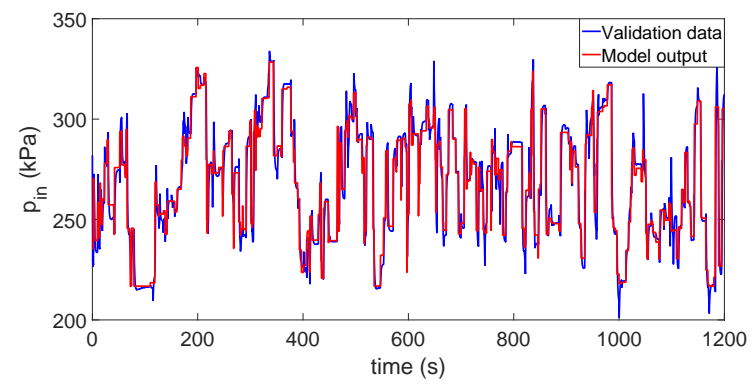

(a)

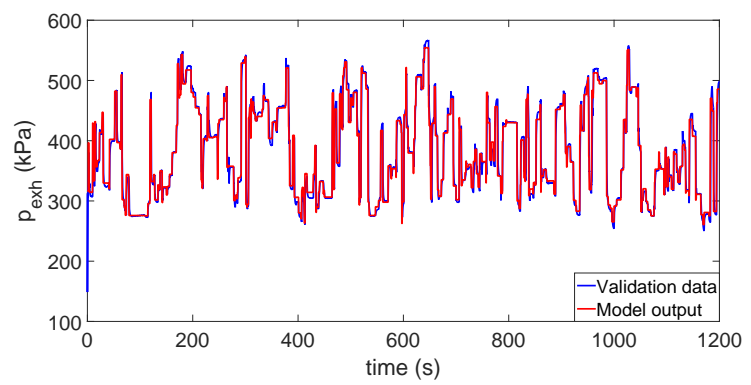

(b)

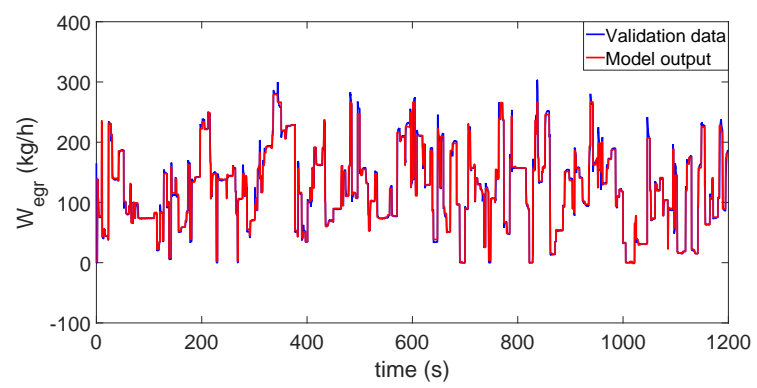

(c)

Figure 7: HILOMOT modelling results at $1800 \mathrm{rpm}, 800$ Nm. (a) $p_{\text {in. }}$ (b) $p_{\text {exh }}$. (c) $W_{\text {egr }}$.

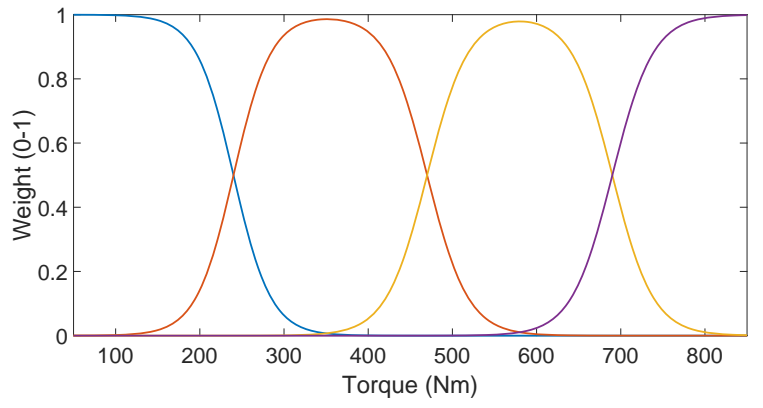

Figure 8: Engine global modelling using HILOMOT

re-constructed using the HILOMOT algorithm with high accuracy, as shown in Fig. 7. The reverse map can be deducted from the explicit functions. Importing the specified values of $p_{\mathrm{in}}, p_{\mathrm{exh}}$ and $W_{\mathrm{egr}}$, the exact values of $\chi_{\mathrm{vgt}}, P_{\mathrm{em}}$ and $\chi_{\text {egr }}$ can be obtained directly.

The neuro-fuzzy modelling method at an engine operating point can also be generalised into engine lobal modelling. 


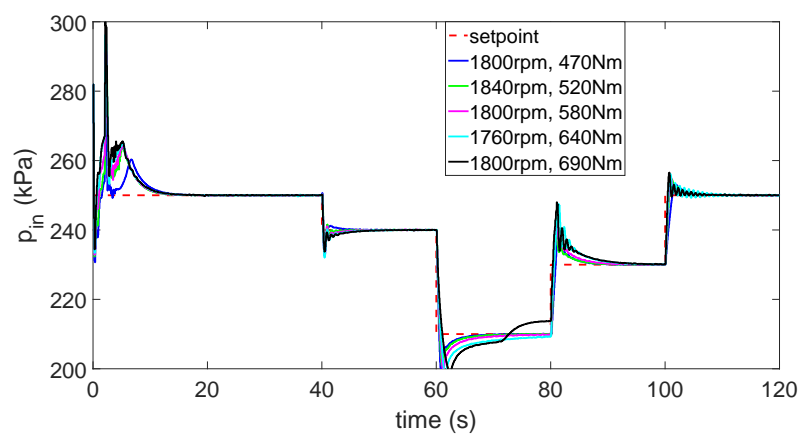

(a)

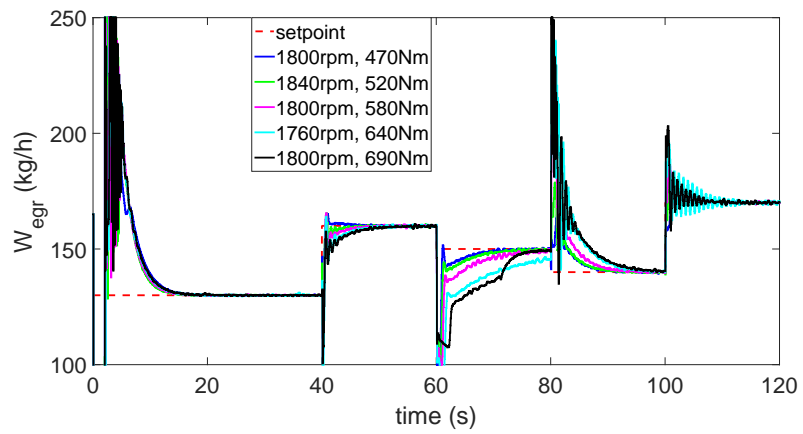

(c)

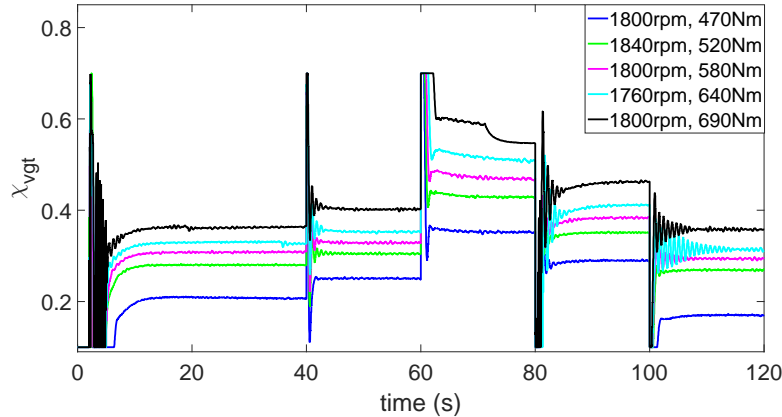

(b)

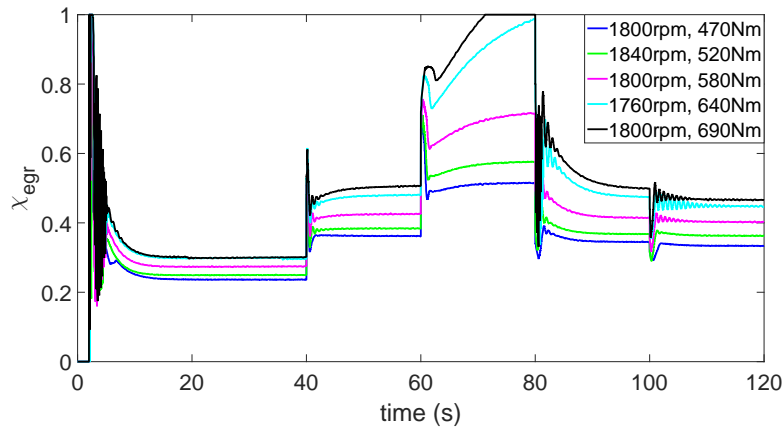

(d)

Figure 9: Tracking performance of the $2 \mathrm{I} 2 \mathrm{O}$ EMPC controller at different operating points. (a) $p_{\text {in }}$ tracking. (b) $\chi_{\text {vgt }}$ (c) $W_{\text {egr }}$ tracking. (d) $\chi_{\text {egr }}$.

In this work, four operating points are selected to generate calibration data: (1800 rpm, $120 \mathrm{Nm}),(1800 \mathrm{rpm}, 360$ $\mathrm{Nm}),(1800 \mathrm{rpm}, 580 \mathrm{Nm})$ and (1800 rpm, $800 \mathrm{Nm})$. The models of the engine operating points locating on the line $N=1800 \mathrm{rpm}, 50 \mathrm{Nm} \leq T_{L} \leq 900 \mathrm{Nm}$ are interpolated from the four neuro-fuzzy models, as shown in Fig. 8.

\section{Simulation Results}

Simulations have been carried out on a physical plant model built in Dynasty, a proprietary multi physics simulation software package used within Caterpillar. The engine manifolds are modeled as one-dimensional components, permitting to capture the pulsations caused by engine actuators operation. All the cylinders are modeled separately to indicate the energy transfer from engine to turbocharger, such that the transient performance is simulated accurately. The compressor and turbine are represented as map based models. The EM is also represented as a mapbased model, whose maximum motoring/generating power are found from a two-dimensional map, with the inputs of turbine speed and power electronics controller setting. The investigated engine is a six-cylinder, 7.01-Liter heavy duty engine with rated power of $225 \mathrm{~kW}$ at $2200 \mathrm{rpm}$ and a rated torque of $1280 \mathrm{Nm}$ at $1400 \mathrm{rpm}$. The engine has been fitted with an experimental turbo-charger for the purposes of this work. The maps used in the paper are all generated from off-line experimental calibration on the instrumented engine. The battery capacity is selected as $0.015 \mathrm{kWh}$.

The validation results of the 2I2O EMPC controller are illustrated in Fig. 9, while the tracking results are shown on the left column, and the control signals are shown on the right column. The controller is developed based on the engine calibrated data obtained at $(1800 \mathrm{rpm}, 580 \mathrm{Nm})$. The controller was tested at five operating points: (1800 rpm, $470 \mathrm{Nm}),(1840 \mathrm{rpm}, 520 \mathrm{Nm}),(1800 \mathrm{rpm}, 580 \mathrm{Nm}),(1760$ $\mathrm{rpm}, 640 \mathrm{Nm})$ and $(1800 \mathrm{rpm}, 690 \mathrm{Nm})$ to verify the robustness against variations on engine running conditions. Different combinations of $p_{\text {in }}^{\star}$ and $W_{\text {egr }}^{\star}$ were set to verify the effectiveness of the controller to track variable setpoints. The tracking performance at the first three operating points are good. With the increased engine load, the response is slower because the control signals take more time to stabilise. In particular, $\chi_{\text {egr }}$ saturates at $(1800 \mathrm{rpm}, 690 \mathrm{Nm}$ ). It shows that the controller has robustness in a neighbourhood of the calibration point. Beyond the boundary of the neighbourhood, another controller has to be built.

The validation results of the 3I3O EMPC controller are illustrated in Fig. 10. $p_{\text {in }}^{\star}$ and $W_{\text {egr }}^{\star}$ have the same settings as in Fig. 9. $p_{\text {exh }}^{\star}$ is set as a sequence of rational constant values according to the calibration data. It is worthy to indicate that the tracking performance is faster than in Fig. 9, in particular when the setpoints have step-up changes. That is because the EM is capable to significantly reduce the turbo lag. 


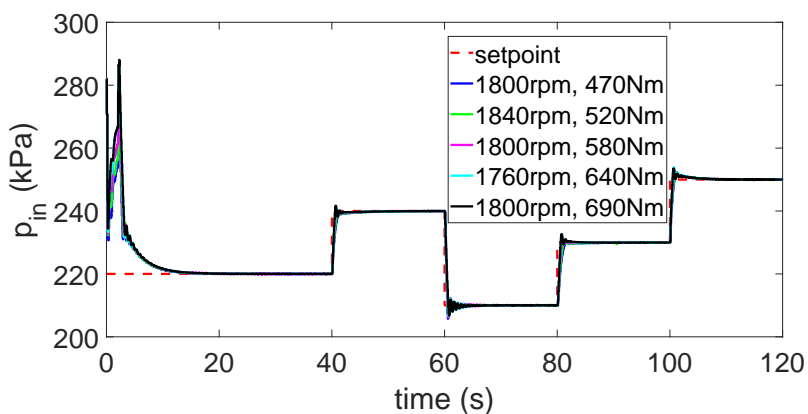

(a)

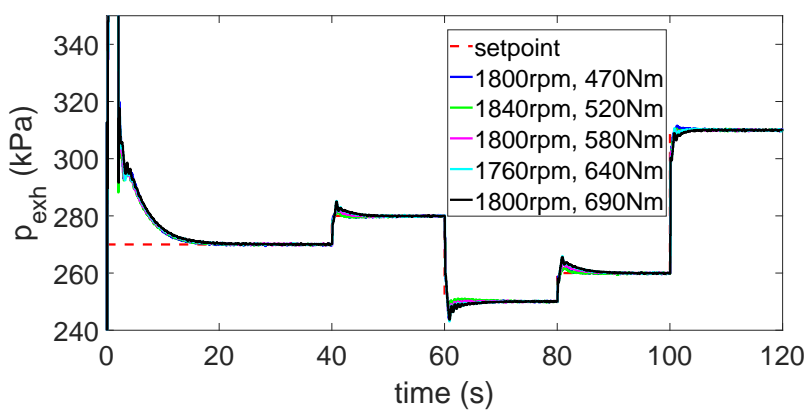

(c)

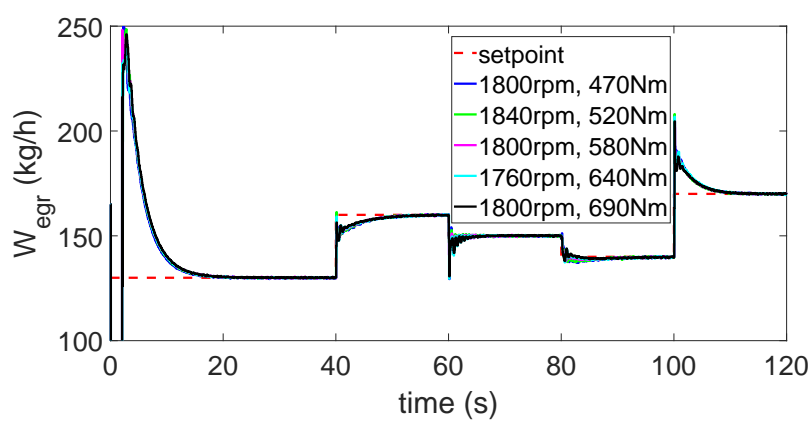

(e)

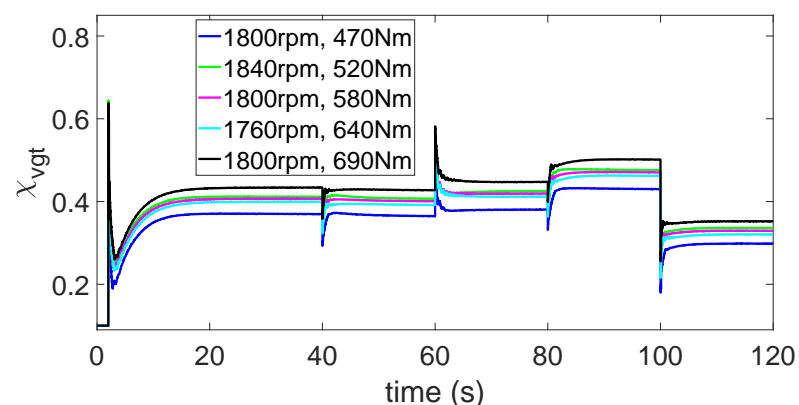

(b)

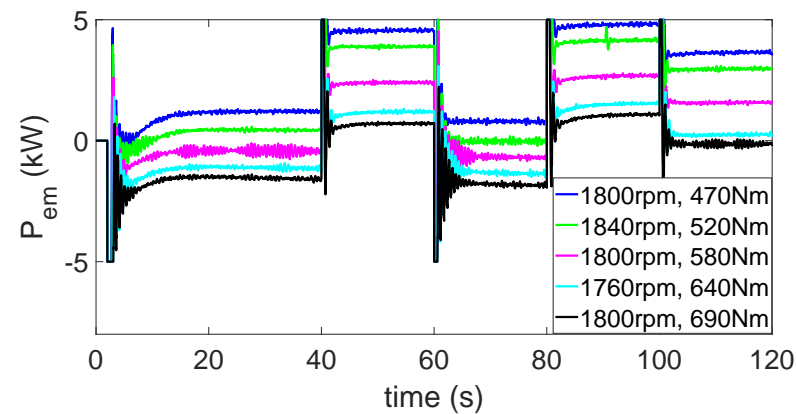

(d)

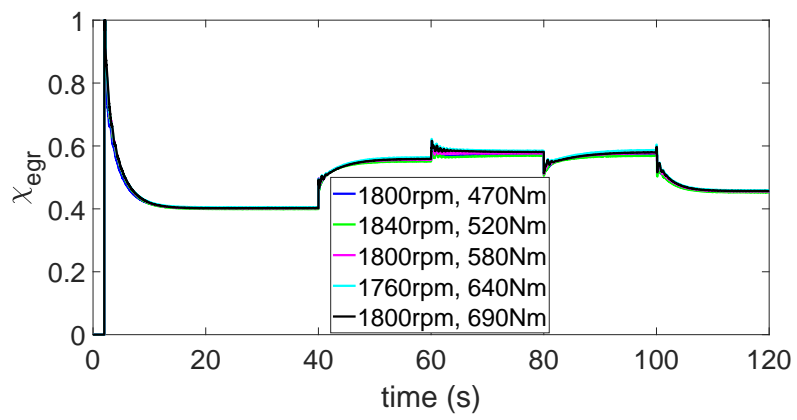

(f)

Figure 10: Tracking performance of the 3130 EMPC controller at different operating points. (a) $p_{\text {in }}$ tracking. (b) $\chi_{\text {vgt }}$. (c) $p_{\text {exh }}$ tracking. (d) $P_{\text {em }}$. (e) $W_{\text {egr }}$ tracking. (f) $\chi_{\text {egr }}$.

The validation results of the two-level energy management strategy are illustrated in Fig. 11. The engine speed is fixed at $1800 \mathrm{rpm}$, while the engine load are selected as random signals between $120 \mathrm{Nm}$ and $780 \mathrm{Nm}$, as shown in Fig. 11(a) and Fig. 11(b), respectively. The initial value of battery SOC was set as 1 . In the first steady state, the engine was regulated by the $2 \mathrm{I} 2 \mathrm{O}$ controller. In the first transient period, the EM works at the full motoring power of $5 \mathrm{~kW}$. Therefore, the battery SOC drops and therefore is expected to be recovered in the second following steady states, as shown in Fig. 11(c). When the 3130 controller is running, the energy management module generates corresponding $p_{\text {exh }}^{\star}$ value to drive the EM working as a generator, as in Fig. $11(\mathrm{~d})$. Meanwhile, $\chi_{\text {vgt }}$ and $\chi_{\text {egr }}$ are tuned simultaneously, as in Fig. 11(e) and Fig. 11(f). Through the multivariable controllers, $p_{\text {in }}$ and $W_{\text {egr }}$ are well regulated, as in Fig. 11(g) and Fig. 11(h).

\section{Conclusion}

A real-time energy management strategy on a state-of-theart ETA for heavy-duty road vehicles is proposed in this paper. To improve the response, the EM within the ETA should run at the maximum motoring power in load acceptance. In steady state, a 2I2O and a 3I3O EMPC controllers were analytically designed to track the setpoints of air path critical variables in a systematic way. When the engine enters steady states from transients, the $3 \mathrm{I} 3 \mathrm{O}$ controller is enabled while the EM works as a generator to recover the battery SOC back. When the desired battery SOC is achieved, the $2 \mathrm{I} 2 \mathrm{O}$ controller will take over. As a result, the EM is free of long continuous running and the thermal regulation of the ETA is easier. A HILOMOT modelling method is adopted to build the energy management strategy and therefore, the setpoint of exhaust pressure is generated in real time. The energy management module and 


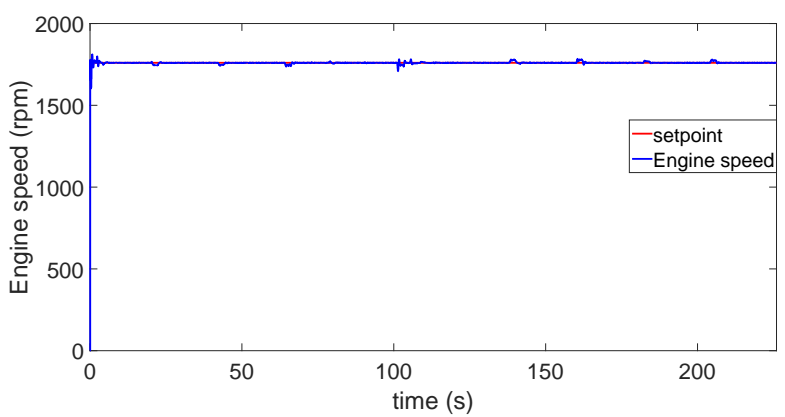

(a)

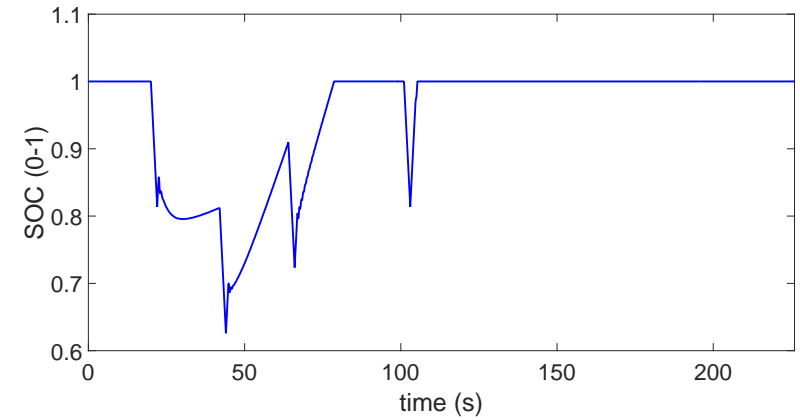

(c)

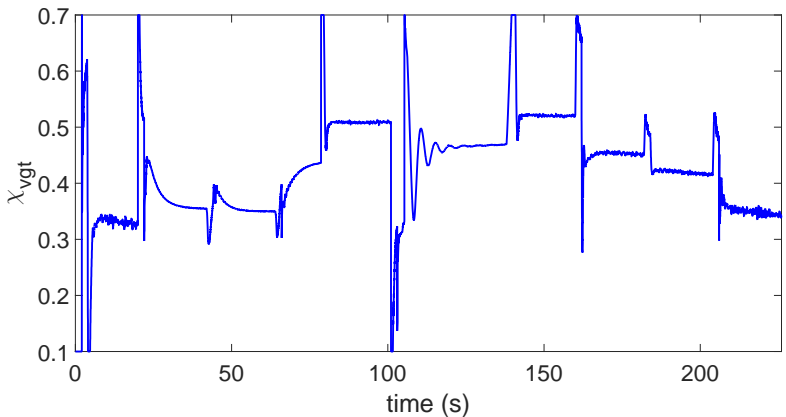

(e)

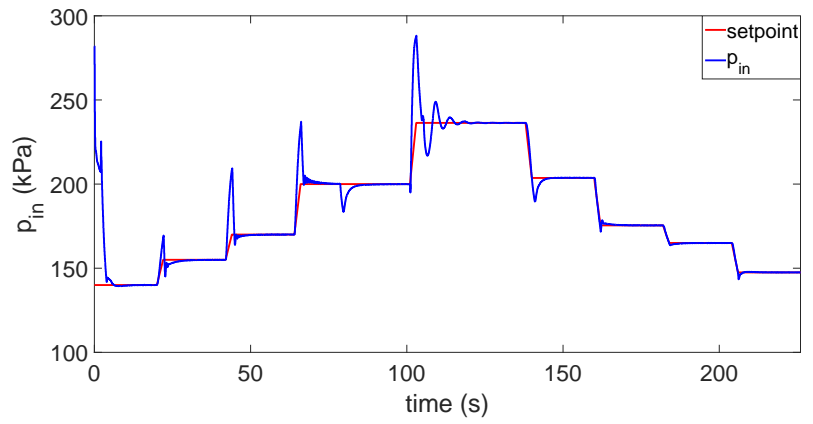

(g)

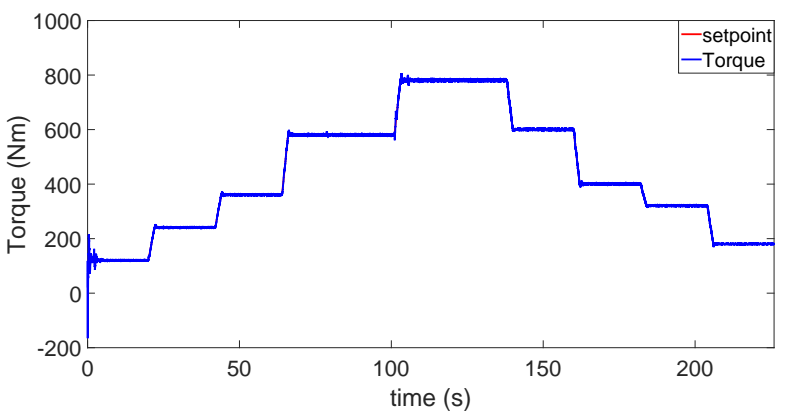

(b)

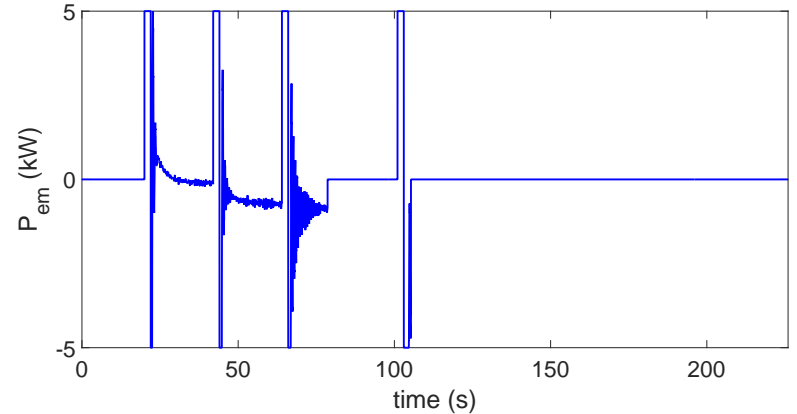

(d)

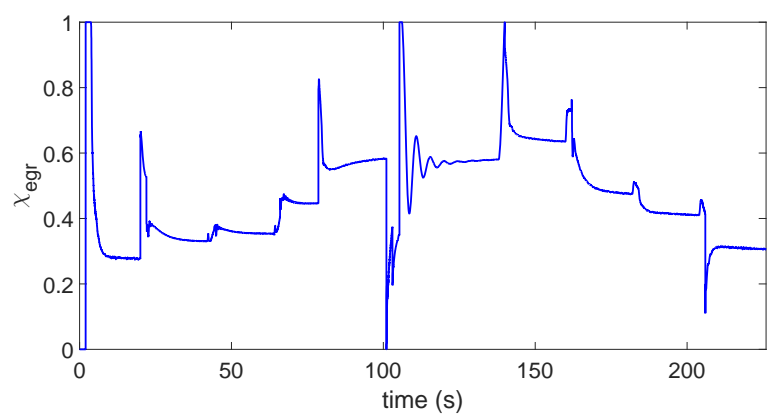

(f)

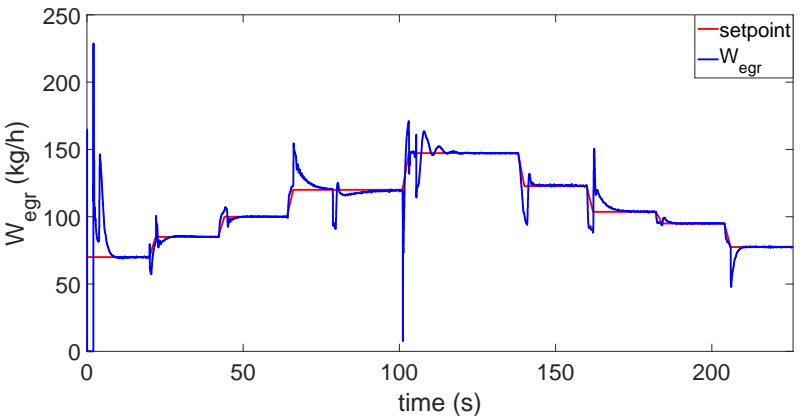

(h)

Figure 11: Energy management results. (a) $N$. (b) $T_{L}$. (c) Battery SOC. (d) $p_{\text {in. }}$ (e) $W_{\text {egr }}$ (f) $\chi_{\text {vgt }}$. (g) $P_{\text {em }}$. (h) $\chi_{\text {egr }}$.

the lower level controller work in a hierarchical way, and consequently the energy flows are timely well distributed. Convincing results are demonstrated in 1-D physical simulations. Future work will focus on experimental validations of the proposed work.

\section{Acknowledgment}

This work was co-funded by Innovate UK, under a grant for the Low Carbon Vehicle IDP4 Programme (TP14/LCV/6/I/BG011L). Innovate UK is an executive body established by the United Kingdom Government to drive innovation. It promotes and invests in research, de- 
velopment and the exploitation of science, technology and new ideas for the benefit of business - increasing sustainable economic growth in the UK and improving quality of life. This work was also co-funded by Engineering and Physical Sciences Research Council of UK under the EPSRC Innovation Fellowship scheme (EP/S001956/1).

\section{References}

[1] C. Patil, S. Varade, S.Wadkar, A review of engine downsizing and its effects, International Journal of Current Engineering and Technology (2017) 319324.

[2] N. Terdich, Impact of electrically assisted turbocharging on the transient response of an off-highway diesel engine, Ph.D. thesis, Imperial College London, London, U.K. (2015).

[3] E. Galloni, G. Fontana, R. Palmaccio, Effects of exhaust gas recycle in a downsized gasoline engine, Applied Energy 105 (2013) 99-107.

[4] D. Gerada, X. Huang, C. Zhang, H. Zhang, X. Zhang, C. Gerada, Electrical machines for automotive electrically assisted turbocharging, IEEE/ASME Transactions on Mechatronics (2018) early access.

[5] X. Xue, J. Rutledge, Potentials of electrical assist and variable geometry turbocharging system for heavyduty diesel engine downsizing, SAE International (2017), 2017-01-1035.

[6] B. Glenn et al., Control design of electrically assisted boosting systems for diesel powertrain applications, IEEE Transactions on Control Systems Technology (2010), vol. 18, no. 4, 769-778.

[7] S. Ibaraki et al., Development of the hybrid turbo, an electrically assisted turbocharger, Mitsubishi Heavy Industries Technical Review (2006), vol. 43, no. 3, 15 .

[8] K. Ekberg et al., Improving fuel economy and acceleration by electric turbocharger control for heavy duty long haulage, IFAC Papers Online (2017), vol. 50, no. $1,1105211057$.

[9] D. Zhao, E. Winward, Z. Yang, R. Stobart, B. Mason, T. Steffen, An integrated framework on characterization, control and testing of an electrical turbocharger assist, IEEE Transactions on Industrial Electronics (2018), vol. 65, no. 6, 4897-4908.

[10] O. Banfer, B. Hartmann, O. Nelles, POLYMOT versus HILOMOT - a comparison of two different training algorithms for local model networks, 16th IFAC Symposium on System Identification (2012) 15691574.
[11] D. Zhao, C. Liu, R. Stobart, J. Deng, E. Winward, G. Dong, An explicit model predictive control framework for turbocharged diesel engines, IEEE Transactions on Industrial Electronics (2014), vol. 61, no. 7, 3540-3552.

[12] L, Teslic, B. Hartmann, O. Nelles, I. Skrjanc, Nonlinear system identification by GustafsonKessel fuzzy clustering and supervised local model network learning for the drug absorption spectra process, IEEE Transactions on Neural Networks (2011), vol. 22, no. 12, 1941-1951.

\section{Contact Information}

Dr Dezong Zhao

Department of Aeronautical and Automotive Engineering Loughborough University

Leicestershire

U.K.

d.zhao@lboro.ac.uk

\section{Mr Wen Gu}

Department of Aeronautical and Automotive Engineering Loughborough University

Leicestershire

U.K.

w.gu@lboro.ac.uk

\author{
Dr Byron Mason \\ Department of Aeronautical and Automotive Engineering \\ Loughborough University \\ Leicestershire \\ U.K. \\ b.mason2@lboro.ac.uk
}

